Piotr ZAWOJSKI

\title{
FOTOGRAFIA I FILM W PRAKTYCE ARTYSTYCZNEJ ORAZ PROPOZYCJACH TEORETYCZNYCH DAVIDA HOCKNEYA
}

Zbadaj wpierw wiedzę, potem weź się do praktyki, zrodzonej z wiedzy. Praktyka musi być zawsze zbudowana na podstawie dobrej teorii, do której perspektywa jest przewodniczką i bramą i bez niej nie zdziałasz nic dobrego w dziedzinie malarstwa ${ }^{1}$.

Leonardo da Vinci

Czy fotografia sprawia, że świat wydaje się nijaki? Tak uważam, gdyż fotografia różni się od człowieka. Aparat widzi świat w zgodzie z zasadami geometrii, a my-psychologii².

David Hockney

Camerę uważa się powszechnie i niesłusznie za wynalazek dziewiętnastowieczny.

Camera nie jest jednak wynalazkiem, jest zjawiskiem przyrodniczym. Rzutowanie optyczne może nastąpić w sposób zupełnie naturalny przez szparę w żaluzji okiennej przyciemnionego pokoju.

Camera obscura oznacza dosłownie „ciemny pokój””.

Nie potrzeba tu ani soczewek, ani luster, chociaż rzutowany obraz będzie ciemny lub nieostry, albo ciemny i nieostry równocześnie. Przy użyciu soczewki umocowanej w większym otworze, obraz będzie jaśniejszy i może być bardzo ostry. Wynalazek fotografii oznaczał w istocie wynalezienie chemikaliów, dzięki którym rzutowaną scenę można było zatrzymać wewnątrz camery.

Ale obrazy rzutowane w camerach oglądano przez setki lat, zanim to się stało. Jeżeli zrozumiemy, dlaczego to jest takie ważne, zrozumiemy też różnicę między

oglądaniem świata w trzech wymiarach i oglądaniem przedstawień świata w dwóch wymiarach ${ }^{3}$.

David Hockney

${ }^{1}$ L. da Vinci, O malarstwie, tłum. L. Staff, Kraków-Budapeszt-Syrakuzy 2019, s. 86, 88.

${ }^{2}$ D. Hockney, M. Gayford, Historia obrazów. Od ściany jaskini do ekranu komputera, tłum. E. Hornowska, Poznań 2017, s. 25.

${ }^{3}$ D. Hockney, Wiedza tajemna. Sekrety technik malarskich dawnych mistrzów, tłum. J. Holzman, Kraków 2006, s. 200. 
Inspiracią do namalowania przez Davida Hockneya Portrait of an Artist (Pool with Two Figures) (1972) - przez krótki okres najdroższego obrazu żyjącego artysty, sprzedanego na aukcji Christie's w Nowym Jorku w listopadzie 2018 roku za rekordową sumę 90 milionów dolarów - były fotografie. Jedna przedstawiała mężczyznę pływającego w basenie, druga - młodzieńca spoglądającego na ziemię. Był nim asystent i partner Hockneya - Peter Schlesinger ${ }^{4}$. Jego wizerunek, będący rodzajem studium do obrazu, został zarejestrowany na pięciu osobnych zdjęciach (głowy i ramion, tułowia, talii, kolan, stóp), co - jak tłumaczył artysta - wydawało mu się o wiele bardziej realistyczne i prawdziwe, niż gdyby został utrwalony za pomocą jednego zdjęcia wykonanego przy użyciu szerokokątnego obiektywu ${ }^{5}$. Po blisko dekadzie od tego doświadczenia Hockney zaczął tworzyć joiners, czyli duże kolaże fotograficzne wykonywane poprzez połączenie w jedną całość kilkudziesięciu zdjęć polaroidowych ${ }^{6}$. Te poszukiwania miały go z kolei doprowadzić do eksperymentów ze sztuką ruchomego obrazu w drugiej dekadzie XXI stulecia.

Tak jak w wielu innych przypadkach fotografie stały się dla niego źródłem inspiracji malarskich, ale też filmowych. Napięcia pomiędzy obrazami fotograficznymi, malarskimi i ruchomymi zachęcają do refleksji nie tylko nad relacjami tych mediów, ujawniającymi się w praktyce artystycznej Hockneya, ale również do przyjrzenia się refleksjom teoretycznym brytyjskiego twórcy. Są one mniej znane niż jego burzliwe życie towarzyskie i uczuciowe, rekordowe sumy osiągane na aukcjach czy też rekordy bite przez zwiedzających jego wystawy. Na przykład retrospektywa w roku 2018 w Tate Modern przyciągnęła blisko pół miliona widzów. David Hockney - pozostając jednym z najsławniejszych artystów światowych - jest niedoceniany jako oryginalny i przeni-

${ }^{4}$ Pierwsza wersja tego obrazu została zniszczona przez malarza, co zostało uwiecznione w A Bigger Splash (1973) w reżyserii Jacka Hazana. W tym filmie dokumentalnym, zrealizowanym w konwencji fly-on-the-wall, pomieszano wątki fikcyjne $\mathrm{z}$ autentycznymi scenami z życia Hockneya i jego otoczenia, głównym motywem zaś jest rozstanie z Peterem Schlesingerem (tytuł jest powtórzeniem tytułu jednego z jego najbardziej znanych obrazów). To jeden z dziesiątków materiałów audiowizualnych poświęconych artyście. Jak mało kto zrozumiał on bardzo wcześnie, że ruchomy obraz to dziś podstawowa forma budowania swego wizerunku i rozpoznawalności, środek komunikowania się z odbiorcami oraz medium kreacji.

${ }_{5}$ Zob. L. Weschler, True to Life: Twenty-Five Years of Conversations with David Hockney, Berkeley-Los Angeles-London 2008, s. 4-6.

${ }^{6}$ Więcej na ten temat można dowiedzieć się z filmu dokumentalnego Dona Featherstone'a David Hockney. Joiner Photographs (1983), < https://www.youtube.com/watch?v=cGtraVb_0vY> [dostęp: 14 lutego 2020]. 
kliwy myśliciel rozprawiający o losach obrazów (zarówno nieruchomych, jak i ruchomych) w dobie rewolucji technologicznej i kolejnych przełomów wizualnych ${ }^{7}$. W tym artykule chciałbym zasygnalizować przenikanie się w działalności Hockneya praktyki twórczej i refleksji teoretycznej, co zaowocowało powstaniem kilku publikacji, w których artysta przedstawił własne poglądy na temat różnych rodzajów obrazów - malarskich, fotograficznych i filmowych. Ja chciałbym się skupić przede wszystkim na jego fotografiach i filmach oraz propozycjach teoretycznych im poświęconych. To fotografia bowiem doprowadziła Hockneya do realizacji audiowizualnych, stanowiła rodzaj wprowadzenia do eksperymentów z ruchomym obrazem.

W początkowym okresie działalności artysty wypowiedzi dyskursywne dotyczące rozmaitych zagadnień sztuki właściwie były nieobecne, co nie znaczy, że już wtedy, czyli w latach 60. i 70. ubiegłego stulecia, nie wykazywał on szczególnego zainteresowania jej teorią, historią i estetyką. W błyskotliwej analizie obrazu Portrait Surrounded by Artistic Devices (1965), namalowanego przez dwudziestoośmioletniego Hockneya, Martin Hammer stawia tezę, że pomimo pozornej „lekkości i zalotności” prac z tamtego okresu można je postrzegać jako dzieła "filozoficzne w swych fundamentach i ambicjach" Zdecydowanie rozszerzyłbym tę opinię także na pozostałe obszary twórczości tego artysty, wykorzystującego różne media, które w pewnych okresach jego działalności odgrywały najważniejszą rolę, w kolejnych były porzucane albo czasowo zarzucane. Ale bez względu na to, jakie medium w danym okresie było główną dominantą praktyki artystycznej, zawsze w centrum jego zainteresowań pozostawały kwestie obrazu i obrazowania, w tym sensie nie ma różnicy, czy były to obrazy malarskie, fotograficzne czy filmowe.

Droga Hockneya to swego rodzaju powtórzenie historycznej ewolucji i progresji mediów wizualnych, także - a może przede wszystkim - w wymiarze technologicznym. Artysta realizuje swoje projekty audiowizualne jako formy instalacyine $z$ przeznaczeniem do pokazów galeryjnych a nie kinowych, sam też dokumentuje swoje wystawy, tworząc filmy przy użyciu zaprojektowanego przez siebie systemu trójkamerowego: The Biggest Picture (2012) prezentuje wystawę w Royal Academy of Arts w Londynie, A Bigger Exhibition (2014) zrealizowany został na wystawie w de Young Museum w San Francisco. Obraz i jego medialne wcielenia często służą do uzmysłowienia specyficznej jed-

7 Maria Poprzęcka pisze, że Hockney to „współcześnie artysta najbardziej, nawet jeśli w sposób szalony, zainteresowany problemami widzenia”. M. Poprzęcka, Inne obrazy. Oko, widzenie, sztuka. Od Albertiego do Duchampa, Gdańsk 2008, s. 161. Szkoda, że autorka nie rozwija szerzej tego zagadnienia.

${ }^{8}$ M. Hammer, Hockney as Philosophical Painter, w: David Hockney, red. C. Stephens, A. Wilson, London 2017, s. 213. 
norodności, ale też dyskretnych - a czasem fundamentalnych - różnic. Natura obrazu (w „perspektywie” - w wielorakim sensie tego słowa - zachodniej) od czasów renesansowego ustanowienia prymatu perspektywy centralnej zasadniczo się nie zmieniła nawet wtedy, kiedy pojawiły się obrazy wirtualne, na co zwraca dobitnie uwagę Jean Claire, dzisiaj to pogląd dosyć powszechnie podzielany, choć nie jedyny. Mówi on o tym, że „przestrzeń wirtualna jest w prostej linii kontynuacją racjonalnej, jednolitej i izotropowej przestrzeni Brunelleschiego" ${ }^{\prime \prime}$. Podobny pogląd wyraża Anthony Vilder, który konstatuje, że „perspektywa nadal jest zasadą w środowiskach wirtualnych; obiekty ciągle są pojmowane i reprezentowane tak jak we wszystkich trójwymiarowych konwencjach osiemnasto- i dziewiętnastowiecznych praktyk", a jedyne, co się zmieniło, to „technika symulacji i co ważniejsze - miejsce oraz pozycja podmiotu lub tradycyjnego "widza" przedstawienia" ${ }^{10}$. Wyrazem innego stanowiska może być przekonanie wyrażane przez Anne Friedberg, która pisze, że „perspektywa zbieżna zakończyła być może swój żywot na komputerowym pulpicie $[\ldots]$, chociaż - jak dodaje - algorytmiczne konstrukcje [...] opierają się na cyfrowej symulacji przestrzeni perspektywicznej, nie wszystkie cyfrowe przestrzenie zaprojektowane są tak, aby sugerować trzy wymiary"11. Fundamentalny paradygmat przedstawiania rzeczywistości na płaskiej, dwuwymiarowej powierzchni, jakim jest perspektywa linearna, obecnie należałoby skonfrontować z nowym paradygmatem. Tak czynią w swoich propozycjach, próbujących odejść od reprezentacjonalistycznej teorii obrazu, Ingrid Hoelzl i Rémi Marie, opisujący rodzaj przejścia od softimages do postobrazów w okresie przełomu cyfrowego. Stary paradygmat określany jest przez nich mianem „fotograficznego paradygmatu obrazu”, nowy zaś nazywają „paradygmatem algorytmicznym"12. Obrazy powstające jako efekt pracy narzędzi obliczenio-

9 J. Claire, Perspectives dépravées, w: D. Hockney, Dialogue avec Picasso, Paris 1999, s. 27. Cyt. za: Poprzęcka, Inne obrazy..., s. 221. Warto przy okazji wspomnieć, że Claire, używając określenia "perspektywa zdeprawowana”, nawiązuje do znakomitych prac litewskiego historyka sztuki Jurgisa Baltrušaitisa, którego opracowania dotyczące różnych form odstępstw od reprezentacji wykorzystujących perspektywę (anamorfozy i dziwaczne perspektywy) mogą i dzisiaj stanowić znakomity materiał do refleksji nad tym, jak teoria sztuki, poddając się prymatowi perspektywy geometrycznej, porzuciła - czy też zmarginalizowała - wiele zagadnień niepasujących do dobrze już opisanych problemów teorii obrazu. Zob. J. Baltrušaitis, Anamorfozy albo Thaumaturgus opticus, tłum. T. Stróżyński, Gdańsk 2009.

${ }_{10}$ A. Vidler, Warped Space. Art, Architecture and Anxiety in Modern Culture, Cambridge-London 2000, s. 7-8.

${ }^{11}$ A. Friedberg, Wirtualne okno. Od Albertiego do Microsoftu, tłum. A. Rejniak-Majewska, M. Pabiś-Orzeszyna, Warszawa 2012, s. 6.

12 I. Hoelzl, R. Marie, From Softimage to Postimage , Leonardo” 2017, 1(50), s. 72-73. Artykuł ten to rodzaj apendyksu do ich książki Softimage: Towards a New Theory of the 
wych, wytwarzane algorytmicznie, ustanawiają nową rzeczywistość, nową widzialność, której istotną cechą jest nie tylko odmienna ontologia, ale przede wszystkim ontogeneza, a zatem sposób powstawania i wytwarzania obrazów będących efektem procedur obliczeniowych.

Sygnalizuję tylko te zagadnienia, bowiem David Hockney wielokrotnie podejmował kwestie związane $z$ rolą perspektywy centralnej w procesie kształtowania się zachodniego paradygmatu reprezentacji, co przyczyniło się w niemałym stopniu do stworzenia sławnej koncepcji znanej jako „teza Hockneya-Falco", spopularyzowanej w Wiedzy tajemnej ${ }^{13}$. Hockney przedstawia ją tak:

Teza, którą tu stawiam, mówi, że od początku XV wieku wielu artystów świata zachodniego korzystało $z$ optyki - rozumiem przez to zwierciadła i soczewki (lub ich kombinacje) - w celu odwzorowywania „na żywo”. Niektórzy artyści tworzyli swoje rysunki i obrazy bezpośrednio dzięki tym projekcjom. Ten nowy sposób odwzorowywania świata - nowy sposób widzenia - szybko się rozpowszechni1 ${ }^{14}$.

By tego dowieść, Hockney przeprowadził szereg eksperymentów, jednym z najbardziej spektakularnych było powtórzenie opisanego przez biografa Filippa Brunelleschiego Antonia di Tuccio Manettiego pokazu perspektywy (sprzed roku 1412), obrazującego baptysterium florenckie San Giovanni, z wykorzystaniem katedry Santa Maria del Fiore (jako swoistej camery obscury) i zwierciadła wklęsłego. Hockney opisał to z kolei w książce oraz przedsta-

Digital Image, Bristol-Chicago 2015. Zob. też: P. Zawojski, Od obrazów (audiowizualnych) do postobrazów (hybrydycznych). Perspektywa teoretyczna, „Przegląd Kulturoznawczy" 2019, 1(39), <https://www.ejournals.eu/Przeglad-Kulturoznawczy/2019/Numer-1-39-2019/art/14649/> [dostęp: 6 lutego 2020].

${ }^{13}$ Hockney, Wiedza tajemna... Warto sięgnąć do kilku artykułów, które w sposób o wiele bardziej zaawansowany - aniżeli uczyniono to we wspomnianej książce, która ma charakter popularny - przedstawiają tezy Hockneya i wspomagającego go swymi badaniami w zakresie optyki Charlesa M. Falco. Zob. D. Hockney, C.M. Falco, The Art of the Science of Renaissance Painting, <https://wp.optics.arizona.edu/falco/wp-content/uploads/ sites/57/2016/08/NatlGallery.pdf> [dostęp: 6 lutego 2020]; D. Hockney, C.M. Falco, Optical Instruments and Imaging: The Use of Optics by $15^{\text {th }}$ Century Master Painters, < https:// www.researchgate.net/publication/228924009_Optical_instruments_and_imaging_The use_of_optics_by_15th_century_master_painters> [dostęp: 8 lutego 2020]; C.M. Falco, Ibn al-Haytham and the origins of Computerized Image, < https://www.researchgate.net/ publication/4319035_Ibn_al-Haytham_and_the_origins_of_computerized_image_analysis> [dostęp: 8 lutego 2020]; C.M. Falco, Optics and Renaissance Art, w: Optics in Our Time, red. M.D. Al-Amri, M. El-Gomati, M.S. Zubairy, New York 2016, s. 265-283.

${ }^{14}$ Hockney, Wiedza tajemna..., s. 12. 
wił w filmie dokumentalnym prezentującym "tezę Hockneya-Falco" i liczne eksperymenty malarza ${ }^{15}$.

David Hockney to przykład teoretyka i filozofa obrazu, który swoje refleksje wywodzi wprost z własnego doświadczenia jako artysty i badacza. Przenikanie się tych ról jest stale obecne w jego pracy artystycznej i refleksjach, tak też było w przypadku jego kilkuletniego intensywnego zajmowania się fotografią w latach 80 . Stała się ona w tamtym okresie ważnym - by nie powiedzieć: podstawowym - środkiem jego wypowiedzi. Praktyka i teoria wydają się dla niego być równie ważne. Świadomość medium, samoświadomość artystyczna i estetyczna artystów to wyraz ducha epoki, w której intuicyjne podejście do sztuki wydaje się niestosowne. Hockney jawi się jako wzorcowy wręcz twórca, niezwykle konceptualnie podchodzący do swojej praktyki artystycznej, będącej konsekwencją jego systematycznie prowadzonych badań nad historią sztuki oraz stale rozwijanym zestawem własnych ustaleń teoretycznych.

Zainteresowanie fotografią u kogoś, kto żyje w świecie obrazów i te obrazy tworzy, wydaje się być czymś naturalnym. David Hockney wyznaje:

Fotografia interesowała mnie zawsze, jak i kwestia tego, czym ona jest. Każdy, kto robi zdjęcia, zastanawia się nad tym. Zadajemy sobie pytanie: czym jest rzeczywistość? Czym jest to, co znajduje się na zdjęciu? Rzeczywistość to pojęcie nieco podejrzane, gdyż rzeczywistości [...] nie da się od nas oddzielić. A to właśnie robi fotografia: oddziela nas od rzeczywistości ${ }^{16}$.

W tych słowach wyrażone są podstawowe wątpliwości związane $z$ fotografią, stale powracające pytanie o jej stosunek do rzeczywistości to w istocie lejtmotyw wielu roztrząsań jej poświęconych, nie wspominając już o pytaniu, czym ona tak naprawdę jest. Dla Hockneya nie ulega wątpliwości, że ludzie od zawsze poszukiwali czegoś takiego jak fotografia, czyli optycznego odwzorowania rzeczywistości, przy czym jej historia jest zdecydowanie dłuższa, niż powszechnie się sądzi. Dziewiętnastowieczne proklamowanie wynalazku fotografii jako nowego wówczas medium wskazuje tylko na możliwości utrwalania obrazów za pomocą „chemikaliów”. Pożądanie zapisania obrazu optycznego wyrasta z renesansowych konceptów związanych z perspektywą

15 David Hockney: Secret Knowledge. Reżyseria: Randall Wright, produkcja: BBC Production, Wielka Brytania 2002.

${ }^{16}$ Hockney, Gayford, Historia obrazów..., s. 246. 
centralną i jednocześnie jego finalną wersją, jaką było wynalezienie fotografii. W tym sensie fotografia stanowi ostatnie ogniwo historycznego procesu rozwoju malarstwa, jego przedłużenie i odnowienie. Nie jest zapewne, co z lubością powtarzali jej krytycy, narzędziem unicestwienia malarstwa, wzajemne relacje tych dwóch mediów są skomplikowane, co uwidacznia się także w twórczości Hockneya.

Przystępując do pracy z fotografią, brytyjski artysta musiał zmierzyć się przynajmniej z kilkoma problemami, które nieustannie go frapowały, przy czym zawsze interesowały go wszystkie rodzaje fotografii "nieczystej” (impure $\left.\right|^{17}$. Wynikało to $z$ naturalnej dociekliwości, ale jednocześnie użycie fotografii jako medium autorskiej wypowiedzi musiało być motywowane poszukiwaniem w fotografii czegoś, czego nie mogło mu zaoferować malarstwo. Punktem wyjścia stała się maksyma Man Raya przywołana w najważniejszym zbiorze rozmów Hockneya poświęconych fotografii. Dodajmy tylko, że ta formuła dialogu jest mu szczególnie bliska, opublikował w ten sposób kilka ważnych książek. W On Photography, rozmawiając z Paulem Joyce'em, Hockney cytuje amerykańskiego fotografa i filmowca: „Fotografuję to, czego nie można namalować, maluję to, czego nie można sfotografować" ${ }^{18}$. Czego zatem, tak jak Man Ray, nie mógł namalować Hockney, a co mógł sfotografować, i przede wszystkim - jak widział podstawową różnicę pomiędzy tymi dwoma sposobami tworzenia obrazów?

Kwestia ta wydaje się być problematyczna, o ile bowiem malarstwo to $\mathrm{w}$ istocie rodzaj konstruowania obrazu "z niczego", ale przy tym na bazie pewnych schematów oraz umiejętności, o tyle obrazy fotograficzne są „zdjęte", wzięte $z$ natury. To, wedle Johna Szarkowskiego ${ }^{19}$, długoletniego kuratora fotografii w MOMA w Nowym Jorku, decyduje o jej nowatorstwie. Dzisiaj, w dobie (także fotograficznego) kompozytowania obrazów digitalnych, rzecz jasna taka teza jest trudna do obrony, w kontekście zaś prac fotograficznych Hockneya ujawnia się jego nowatorskie podejście i swoista antycypacja strategii cyfrowego tworzenia obrazów w czasach dominacji technologii analogowych. Po to, by przemyśleć na nowo swoje podejście do malarstwa, artyście potrzebna była próba przekroczenia jego ograniczeń, co w efekcie skłoniło go do sformułowania przewrotnej tezy o wyższości malarstwa nad fotografią w zakresie, na przykład, możliwości odtwarzania rzeczywistości zgodnie $z$ regułami i logiką naszego podmiotowego widzenia. Naiwna wiara w repro-

17 M. Gayford, A Bigger Message. Conversation with David Hockney, London 2016, (Kindle), s. 115,5.

${ }_{18}$ Hockney on Photography. Conversation with Paul Joyce, London 1988, s. 43.

19 J. Szarkowski, The Photographer's Eye, New York 1966, s. 6. 
dukcyiną doskonałość aparatów technicznych długo traktowana była z całą powagą i także dziś nie brakuje zwolenników takiej tezy, podczas gdy niewiele ma ona wspólnego z rzeczywistością, tak jak tradycyjne obrazy fotograficzne nie przedstawiają jej w sposób prawidłowy. Ale być może ważniejszy jest fakt, że w istocie nie poszerzają one naszej wiedzy, tak jak nie poszerzają naszych możliwości widzenia i zobaczenia kształtu świata w jego pełni. Nie myślę w tym momencie o takich aparatach do wytwarzania obrazów, jak na przykład kosmiczny teleskop Hubble'a czy skaningowy mikroskop elektronowy (SEM), które w rewolucyjny wręcz sposób poszerzają naszą wiedzę, tyle że niewiele mają wspólnego $z$ tradycyjną fotografią.

Tym, co szczególnie interesowało Hockneya, była wspominana już kwestia perspektywy, a także kwestia widzenia jednoocznego, problematyka czasu (lub jego braku) oraz nienaturalna sytuacja „zatrzymania” naszego ruchomego ciała w trakcie wykonywania zdjęcia. Nawet bowiem kiedy my się zatrzymujemy, to nasze oko jest nieustannie ruchome, a przy tym wszystko to, co widzi, jest ostre, jak twierdzi Hockney. Dlatego punktem odniesienia dla jego poszukiwań w zakresie fotografii było odwołanie do kubizmu, w szczególności do praktyki Pabla Picassa ${ }^{20}$, którego twórczość stała się dla niego niezwykle inspirująca, dlatego że on widział więcej niż ktokolwiek inny. To, co szczególnie ciekawiło Hockneya w twórczości Picassa i co starał się osiągnąć w swoich fotografiach, to nowe ujęcie przestrzeni. Jak mówi: „[...] na obrazach Hiszpana widać postać jednocześnie z przodu i z tyłu. Tak jakby widz obchodził ją dookoła. Dlatego jest to rodzaj obrazu z pamięci, ale też obrazu w ruchu - filmu. Właśnie takie obrazy tworzymy w wyobraźni" ${ }^{21}$. A przy tym kubistyczne ujęcie rzeczywistości w nowatorski sposób projektuje pozycję widza, który przestaje być zdystansowanym wojerem, wchodząc w obraz, staje się uczestnikiem, dziś nazwalibyśmy go interaktorem bądź vuserem, co zapowiada także przyszły rozwój środowisk immersyjnych, związanych z wykorzystaniem na przykład Virtual Reality ${ }^{22}$. Pamiętając przy tym, że takie przestrzenie immersyjne, czy też złożone instalacje, mają swoją wspaniałą antycypację. Niegdyś zwrócił na to uwagę Bill Viola,

${ }^{20}$ W On Photography Hockney wielokrotnie przywołuje prace i poglądy Picassa, warto też dodać, że w trakcie odbywającej się w Guggenheim Museum w Nowym Jorku w roku 1984 wystawy Picasso: The Last Years, 1963-1973 Hockney wygłosił wykład zatytułowany Picasso: Paintings of the '60, w którym mówił o wpływie późnej twórczości hiszpańskiego artysty na jego prace fotograficzne, <https://www.guggenheim.org/wp-content/ uploads/2018/08/9009139_01_9009140_01-Picasso-Paintings-of-the-1960s.pdf> [dostęp: 30 kwietnia 2020].

${ }^{21}$ Hockney, Gayford, Historia obrazów..., s. 302.

22 Por. Hockney on Photography..., s. 115. 
przywołując arcydzieło Giotta - freski w kaplicy Scrovegnich w Padwie, wykonane na początku XIV stulecia.

To gigantyczny obraz trójwymiarowy, do którego się wchodzi. Powierzchnia wszystkich ścian i sklepienia, każdy centymetr kwadratowy wnętrza kaplicy, zostały pokryte malowidłami wykonanymi przez artystę. To jedno z największych dzieł sztuki instalacji na świecie ${ }^{23}$.

Picasso oczywiście w inny sposób pozwala na to, by widz był w obrazie, ale to szczególnie interesowało też Hockneya, kiedy na początku roku 1982 przystąpił do realizacji joiners.

Kubizm to nie był styl, kierunek, to była rewolucyjna postawa wobec rzeczywistości, radykalnie dekonstruująca albertiańską ideę obrazu jako okna obramowującego jakiś wycinek rzeczywistości, która znalazła swoje zwieńczenie w medium fotografii. David Hockney, wychodząc $z$ takich przesłanek, na początku lat 80. zaczyna tworzyć polaroidowe kolaże, w których jego przemyślenia dotyczące fotografii, obrazu i obrazowania zaczynają się materializować. Tradycyjna fotografia wydaje mu się medium nieradzącym sobie z przestrzenią, operuje wizerunkami powierzchniowymi, które nie tyle przedstawiają świat, ile go skutecznie ukrywają, bowiem

[... można skopiować dwa wymiary, ale nie można „skopiować” trzech wymiarów na dwa. To jest sedno moich rozważań: artyści nie zawsze widzieli rzeczy w przestrzeni trójwymiarowej, ale widzieli dwuwymiarowe obrazy, które oddziaływały na nich bardziej niż wrażenia przestrzenne ${ }^{24}$.

I choć stereoskopia pojawia się już w roku 1838 (zwierciadlany stereoskop Charlesa Wheatstone'a), a po premierze przełomowego Avatara (2009) Jamesa Camerona pojawiły się głosy, że to ostateczne zwycięstwo techniki trójwymiarowej, to jednak nic takiego się nie stało. Od kilku lat rozwija się, to prawda, Cinematic VR, jednakże trudno sobie wyobrazić, by w najbliższej przyszłości wszelkiego rodzaju obrazy dwuwymiarowe miały zostać zastąpione przez obrazy 3D.

Sam Hockney swoją twórczość fotograficzną dzieli na trzy obszary: są to kompozycje polaroidowe, kolaże fotograficzne oraz obrazy fotograficzne ${ }^{25}$.

${ }^{23}$ J.G. Hanhardt, Bill Viola Interviewed by John G. Hanhardt, w: Bill Viola. Electronic Renaissance, red. A. Galansino, K. Perov, Firenze 2017, s. 141.

${ }^{24}$ Hockney, Wiedza tajemna..., s. 218.

${ }^{25}$ Hockney używa określenia photographic drawings, które jest wieloznaczne: chodzi o kompozycje kolażowe drukowane na papierze i zamontowane na płytach Dibond, odnosi 
Zajmę się w tym miejscu właściwie jedynie kompozycjami tworzonymi przy wykorzystaniu Polaroida, nie tylko dlatego, że są one chronologicznie najwcześniejsze, ale także dlatego, iż na ich przykładzie można pokazać, co w istocie dla Hockneya stało się ważnym obszarem poszukiwań i eksperymentów związanych z obrazem fotograficznym. Geneza jego dosyć przypadkowego zetknięcia się z techniką polaroidową została już pieczołowicie opisana ${ }^{26}$, dlatego bez powtarzania tych okoliczności chciałbym krótko przedstawić istotę pomysłów związanych z joiners. Tego określenia zaczął używać sam Hockney w odniesieniu do dużych kompozycji fotograficznych, które powstawały w efekcie użycia Polaroida SX-70. Przypomnę, że tego typu aparaty zostały wprowadzone do powszechnego użycia już w roku 1947 , ale dopiero na początku lat 70 . stały się popularne, przede wszystkim z powodu możliwości uzyskiwania niemal natychmiastowego (bez obróbki chemicznej, w ciągu kilku minut) obrazu fotograficznego. Hockney nie był pierwszym artystą, który dostrzegł potencjał kreacyjny w istniejącym wtedy - to znaczy na początku lat 80. - już kilkadziesiąt lat narzędziu, choć lista twórców z niego korzystających nie była zbyt długa. Byli to tacy fotograficy, jak: Lucas Samaras, Joyce Neimanas, Robert Heinecken i przede wszystkim belgijski artysta Stefan de Jaeger, który w latach 1979-1981 tworzył Polaroid Friezes, oskarżając zresztą Hockneya o plagiat i wykorzystanie jego pomysłów fotograficznych. Hockney zarzekał się, że nigdy wcześniej nie widział prac de Jaegera, więc trudno posądzać go o jakąś formę zapożyczenia czy kradzieży pomysłów. Nie ulega wszak wątpliwości, że prace Stefana de Jaegera pochodzące z cykli Sans titre (1980-1982) czy B7 (1980-1982), a więc powstałe bezpośrednio przed pracami Hockneya, oparte są na podobnym koncepcie co joiners.

Mając w pamięci jego stałe zainteresowanie kwestią perspektywy, jednego punktu widzenia, obecnością czasu bądź też jego nieobecnością w fotografii, oraz problemami przestrzeni, kiedy oglądamy joiners mamy wrażenie, jakby wszystkie te zagadnienia zostały w nich zawarte. Ważna jest twórcza reinterpretacja zapoczątkowanego przez kubistów - przede wszystkim przez Picassa - pytania o możliwość dotarcia do istoty naszego widzenia oraz przekroczenia perspektywicznego ujmowania rzeczywistości, które w istocie będąc

się ono zarówno do „rysunków”, jak i „obrazów”. Wspominane w artykule prace można zobaczyć na stronie artysty: <http://www.hockney.com/works> [dostęp: 14 lutego 2020] oraz na stronie The David Hockney Foundation: < https://thedavidhockneyfoundation. org/ > [dostęp: 14 lutego 2020].

26 Zob. C.S. Sykes, David Hockney. The Biography, 1975-2012. A Pilgrim's Progress, New York-London-Toronto-Sydney-Auckland 2014, s. 157-183. 
„formą symboliczną", jak twierdził Erwin Panofsky27, zawłaszczyło naszą percepcję i nasze pojmowanie tego, czym jest odtwarzanie rzeczywistości. Hockney, analizując obrazy hiszpańskiego artysty, zwraca uwagę przede wszystkim na te aspekty, które odnoszą się do przełamania monopolu jednego punktu widzenia i włączenia w konstruowanie obrazu elementów pochodzących z pamięci malarza. Ta zaś obejmuje zarówno wizerunki utrwalone niejako w fotograficzny sposób, jak i czysto subiektywne reminiscencje niepoddające się obiektywnej weryfikacji ${ }^{28}$.

Powstało około 150 kompozycji polaroidowych w ciągu raptem trzech miesięcy bardzo intensywnej pracy, z których kilka zostało pokazanych w lipcu 1982 roku na wystawie „David Hockney. Photographie” w Centre Pompidou w Paryżu ${ }^{29}$. Do najbardziej znanych kompozycji wykonanych przez Hockneya przy użyciu Polaroida należą: My House, Montacalm Avenue (1982), Kasmin Smoking (1982), David Graves, Pembroke Studios (1982), Steve Cohen, Ian, Gary, Lindsay, Doug, Anthony, Ken (1982), Unfinished Painting in Finished Photograph(s) (1982), Don and Christopher (1982), George Lawson and Sleep (1982), Still Life Blue Guitar (1982), Mother (1982). Każda kompozycja składa się z od kilkudziesięciu do stu kilkudziesięciu elementów, czyli pojedynczych zdjęć wykonanych Polaroidem, a zatem kwadratowych, co kojarzyć się może z pikselem jako najmniejszą częścią obrazu wyświetlanego na ekranie, monitorze bądź wyświetlaczu. Sposób kompozytowego tworzenia - polegający na wykonaniu bardzo wielu zdjęć niejako analitycznie rozbijających całą kompozycję po to, by w procesie syntezy uzyskać zupełnie nową jakość opartą na przemyślanej konstrukcji - bliższy jest zdecydowanie procedurom znanym $z$ nowych mediów cyfrowych aniżeli tradycyjnej fotografii ${ }^{30}$. Ten sposób tworzenia czegoś, co dla samego Hockneya nie było już fotografią, można potraktować jako rodzaj symbolicznego przejścia pomiędzy dwoma mediami: fotografią tradycyjną i cyfrową. Jak mówi Fred Ritchin: „Fotografia przez 150 lat będąca przede wszystkim medium percepcji, teraz staje się w dużej mierze

27 Zob. E. Panofsky, Perspektywa jako „forma symboliczna”, tłum., wstęp i posłowie G. Jurkowlaniec, Warszawa 2008.

28 Por. Hockney, Picasso: Paintings of the '60...

29 Zob. D. Hockney, That's the Way I See It, London 1993, s. 89.

${ }^{30}$ Gwoli ścisłości i medialnej archeologii można tylko przypomnieć, że już w roku 1857 powstało niezwykłe „kompozytowe” dzieło Oscara Gustave'a Rejlandera Two Ways of Life, które zostało stworzone z ponad trzydziestu negatywów. Ten fotomontaż można uznać za pionierskie przedsięwzięcie w zakresie tworzenia kompozycji fotograficznych całkowicie zrywających z postrzeganiem fotografii jako realistycznego medium, utrwalającego rzeczywistość w jej obiektywnym kształcie. Por. L. Lechowicz, Historia fotografii, cz. 1: 1839-2009, Łódź 2012, s. 113-115. 
medium konceptualnym"31. Wiele $z$ tych prac to portrety w szczególny sposób prezentujące najczęściej bliskie malarzowi osoby, których fotograficzne wizerunki odbiegają od tradycyjnego ich przedstawiania, ale ujawniają przy tym głębszą prawdę w wymiarze zarówno wizualnym, jak i psychologicznym.

Możliwość natychmiastowego podglądu wykonywanych zdjęć i tworzenia złożonych kompozycji przełamujących dominującą do tej pory zasadę jednego punktu widzenia, co jest próbą oddania ruchliwości naszego spojrzenia, a także tworzenie nowej przestrzeni obrazowej, w której uwidocznia się czas według Hockneya daje w efekcie obrazy, które są „bardziej przestrzenne niż jakiekolwiek fotografie stereoskopowe" ${ }^{\prime \prime 2}$. Oddają one w o wiele bardziej doskonały sposób nasze widzenie przestrzeni i obiektów w niej znajdujących się, co można uznać za udaną adaptację lekcji, jaką dał nam kubizm, ale poprzez wykorzystanie „urządzenia [aparatu - P.Z.] do przedstawiania trójwymiarowych obiektów na dwuwymiarowej powierzchni za pomocą fragmentarycznych spojrzeń na ich różne części”33. To widzenie obojga oczu będących w ruchu, nawet jeśli obserwator pozostaje nieruchomy, choć sam fotografujący musiał się poruszać, wykonując te kompozycje, choćby z tego powodu, że Polaroid ma obiektyw, który nie umożliwia zmiany ogniskowej. Tradycyjna fotografia, uznawana za medium, które w sposób najbardziej realistyczny przedstawia rzeczywistość, to jedno ze złudzeń zarówno widzów, jak i wielu teoretyków. Takie przekonanie Hockneya wydaje się dyskusyjne, stąd jednak można wywieść jego próby poszukiwania alternatywnych rozwiązań związanych z wykorzystaniem medium fotografii.

Po bardzo krótkim i niezwykle intensywnym okresie pracy z Polaroidem artysta zamienia go na prostego Pentaxa 110, za pomocą którego wykonuje szereg kolaży fotograficznych, takich jak Telephone Pool (1982), Merced River, Yosemite Valey (1982), Walking in the Zen Garden at Ryoanji Temple, Kyoto (1983), Sitting in the Zen Garden at Ryoanji Temple, Kyoto (1983), Photographing Annie Leibovitz While She Is Photographing Me, Mojave Desert (1983), Pearblossom Highway (1986). W roku 1983 artysta odwiedził Japonię, co związane było $z$ jego zainteresowaniami japońskimi i chińskimi zwojami, które ukazują rzeczywistość w sposób całkowicie odmienny od europejskiego, wedle artysty są one o wiele bardziej realistyczne aniżeli obrazy wykorzystujące perspektywę centralną. Sam, eksperymentując z odwróconą perspektywą, poszerzał tym samym refleksje teoretyczne na temat obrazowa-

${ }^{31}$ F. Ritchin, In Our Own Image. The Coming Revolution in Photography. How Computer Technology is Changing Our View of the World, New York 1999, s. 124.

32 Hockney on Photography..., s. 25.

${ }^{33}$ M. Livingston, David Hockney, London 1987, s. 235. 
nia o nowe aspekty. Jednocześnie jednak stopniowo jego zainteresowanie fotografią ustępowało przekonaniu, że malarstwo może być zdecydowanie bardziej zaawansowanym sposobem przedstawiania rzeczywistości, jak również zbliżania się do oddania fenomenu ludzkiego widzenia, które nie jest poddane reżimowi jednego punktu widzenia, co zdominowalo myślenie o prawidłowościach przedstawiania świata w malarstwie zachodnim. Percypując chińskie zwoje, widz nie jest zdeterminowany granicami obrazu - może je oglądać, zmieniając punkt widzenia, wędrując pomiędzy motywami przedstawionymi na obrazie; proces ten odbywa się w czasie, tak jak doświadczanie muzyki i literatury ${ }^{34}$.

W grudniu 1983 roku w Victoria and Albert Museum w Londynie Hockney wygłosił swój pierwszy wykład na temat fotografii, który spotkał się z chłodnym przyięciem, zwłaszcza wśród fotografów. W wystąpieniu tym postawił tezę, że spojrzenie $z$ wielu punktów i w różnych momentach czasu lepiej oddaje naturę ludzkiego widzenia ${ }^{35}$. David Bailey, którego postacią inspirował się Michelangelo Antonioni, tworząc postać Thomasa w Powiększeniu (1966), ostentacyjnie opuścił wykład przed końcem. Wystawa wybranych prac fotograficznych w Hayward Gallery również nie wzbudziła jakiegoś powszechnego zachwytu, co być może przyczyniło się do zdecydowanego zmniejszenia aktywności Hockneya jako fotografa. Z fotografii jednak całkowicie nie zrezygnował, czego dowodem mogą być jego obrazy fotograficzne (photographic drawings) wykonywane w ostatnich kilku latach, w których podejmowane są właściwie wszystkie zagadnienia pojawiające się we wcześniejszych realizacjach polaroidowych oraz kolażach fotograficznych. Zmieniła się technologia, Hockney wykorzystuje instrumentarium cyfrowe, warto dodać, że już w roku 1989 został on zaproszony przez Adobe na prezentację programu graficznego Photoshop w Sillicon Valley. Zawsze bliskie mu były wszelkie nowości technologiczne - używał faksów (fax art), iPoda i iPhona jako szkicowników, tworzył „sztukę Xerox”, uznając maszynę kopiującą za specyficzną maszynę drukarską, wykorzystywał software'y komputerowe, tworząc grafiki cyfrowe. Po latach w wywiadzie mówił, że Photoshop uświadomił mu, iż fotografia fotochemiczna się skończyła, jednocześnie jednak dodawał, że program ten doprowadził do niesłychanej homogenizacji estetycznej w świecie

${ }^{34}$ Por. M. Tanaka, Rethinking David Hockney's „reverse perspective”: The Acceptance of Japanese art in the 1970s and 1980, „Aesthetics” 2018, 21, s. 55-68. Tanaka zwraca uwagę, że Hockney często odwoływał się w tym kontekście do tez postawionych przez George'a Rowleya w książce Principles of Chinese Paintings, Princeton 1974, s. 61.

35 Zob. D. Hockney, David Hockney on Photography: A Lecture at the Victoria and Albert Museum. November 1983, New York 1983. 
obrazów ${ }^{36}$. Perspective Should Be Reversed (2014) - komputerowo wykonany kolaż, na który składają się osobno wykonane zdjęcia cyfrowe, zmontowane w jeden zaskakujący swą kompozycją obraz - można uznać za rodzaj zwieńczenia jego wieloletnich poszukiwań w zakresie eksperymentów z perspektywą, obraz składający się z wielu obrazów i wielu perspektyw. „Perspektywa powinna być odwrócona" - ten tytuł jest swego rodzaju manifestacją poglądów teoretycznych Hockneya, nieprzypadkowo jednym z elementów tej kompozycji jest okładka książki Picasso and Truth T.J. Clarka ${ }^{37}$, reinterpretującego twórczość Pabla Picassa - to czytelny sygnał dotyczący inspiracji i pola odniesień. Na leżącej na stole kartce możemy doczytać: „szczególnie dla fotografii”. Fotografia, obecnie prawie wyłącznie w postaci cyfrowej, powtarza ciągle według Hockneya - stare grzechy obrazów zdominowanych przez tradycyiny paradygmat prezentowania rzeczywistości oparty na perspektywie centralnej. Czyżby wieloletnia krucjata artysty, starającego się nie tylko w sposób teoretyczny, ale i praktyczny to zmienić, na niewiele się zdała? Wiele wskazuje na to, że tak właśnie jest.

David Hockney stale poszerzał zestaw środków artystycznego wyrazu i mediów, z jakich korzystał, wydaje się więc czymś naturalnym, że po doświadczeniach $z$ eksperymentami fotograficznymi zwrócił się w stronę ruchomego obrazu. Nie byłby jednak sobą, gdyby nie uczynił tego na własnych warunkach, a przy tym kontynuując swoje zainteresowania teoretyczne i praktyczne sposobami tworzenia i prezentowania obrazów. Jego twórczość filmową można usytuować w kontekście nurtu we współczesnej sztuce określanego mianem art cinema ${ }^{38}$, choć i na tym tle jawi się ona jako zjawisko osobne. Zdefiniowanie tego nurtu nie jest zadaniem łatwym, tym bardziej że

36 Zob. wywiad przeprowadzony w Luisiana Museum of Modern Art przez Christiana Lunda, w trakcie wystawy prac Davida Hockneya w roku 2011, < https://www.youtube. com/watch?v=oAx_aYGmpoM> [dostęp: 14 lutego 2020].

${ }^{37}$ Zob. T.J. Clark, Picasso and Truth. From Cubism to Guernica, Princeton-Oxford 2013.

38 Pojęcie art cinema odnoszone bywa obecnie do takich twórców, jak Michael Haneke, Lav Diaz, Abbas Kiarostami czy Apichatpong Weerasethakul. Zob. G. King, Positioning Art Cinema. Film and Culture Value, London-New York 2019. Tę listę można byłoby zdecydowanie poszerzyć i wspomnieć o takich wybitnych artystach ruchomego obrazu, jak Bill Viola, Matthew Barney, Zbigniew Rybczyński, Pipilotti Rist, Christian Marclay, Robert Cahen, Chris Marker, Harun Farocki, Lech Majewski, Chris Cunningham, Peter Greenaway. 
wchodzi on w szereg rozmaitych koneksji z takimi terminami (i zjawiskami), jak film eksperymentalny, kino niezależne, ale też video art. Generalnie chodzi o rozmaite działania z wykorzystaniem kamer, dziś prawie wyłącznie cyfrowych, które lokują się poza mainstreamem filmowym i najczęściej także poza kinem. Perspektywa filmoznawcza podsuwa tu jeszcze wiele innych tropów, takich jak chociażby kino autorskie, pamiętać musimy także o kolejnej dystynkcji - art cinema i cinema of art, z których to pierwsze określenie odnosi się do kina artystów, drugie zaś - do długiej tradycji filmu artystycznego (art film) ${ }^{39}$. Twórczość filmową Hockneya można rozpatrywać przez pryzmat obu tych kategorii, ale także w kontekście zmian, jakie spowodowane zostały ekspansją nowych mediów. Dodatkowo uwzględnić należałoby proces, który symbolicznie można by określić jako wyjście filmu z sali kinowej i migrację do przestrzeni galeryjnych i muzealnych (black box versus white box). Opisująca ten proces Erika Bolsom ${ }^{40}$ odwołuje się do tradycji badań zarówno filmoznawczych, jak i tych poświęconych współczesnej sztuce, nie stroniąc od optyki konwergencyinej w tym zakresie. Autorka, nawiązując m.in. do Raymonda Belloura, rozwija własne rozumienie terminu „inne kino”41, które oznaczać miałoby realizacje zrywające $z$ dominacją fabuły i konwencjonalnymi sposobami narracji czy też nietradycyjne formy dokumentalne, dekonstruujące wypracowane przez dziesięciolecia elementy formalne języka filmu.

W odniesieniu do twórczości Hockneya swego rodzaju potwierdzeniem, że jego prace można umieścić w tym nurcie, równie ważne wydają się zasadnicze zmiany dokonujące się w formie (i miejscach) prezentacji filmu. O ile obecność sztuki wideo w galeriach i muzeach ma długą historię, o tyle obecność filmu w postaci cinéma d'exposition (termin Jeana-Christophe'a Royouxa) czy gallery film (termin Catherine Fowler) jest zjawiskiem zapoczątkowanym w latach 90. ubiegłego wieku ${ }^{42}$. Filmy pokazywane w galeriach, najczęściej w formie instalacji jednokanałowych lub wielokanałowych, ale też wystawy tematyczne poświęcone wybitnym twórcom kina prezentowane w muzeach, dziś już raczej nikogo nie dziwią. Jako przykłady niech posłużą: pokazywana w Muzeum Narodowym w Krakowie w roku 2014 wystawa

39 Por. L. Koepnick, The Long Take. Art Cinema and the Wondrous, Minneapolis-London, 2017, s. 30 .

40 E. Bolsom, Exhibiting Cinema in Contemporary Art, Amsterdam 2013.

${ }^{41}$ Używa ona określenia othered cinema w odróżnieniu od other cinema stosowanego m.in. przez Belloura, co waloryzuje semantycznie rodzaj odejścia, zerwania łączności z kinem tradycyjnym. Zob. Bolsom, Exhibiting Cinema..., s. 9 i dalsze partie książki.

${ }^{42}$ Pomijam w tym miejscu istotne zagadnienie problematycznego dziś rozróżnienia dzieł filmowych i prac wideo. 
Stanleya Kubricka ${ }^{43}$ czy retrospektywna prezentacja twórczości filmowej i wideo Lecha Majewskiego w MOMA w Nowym Jorku w roku 2006, zatytułowana "Conjuring the Moving Image" 44 .

W takim kontekście można też umieścić twórczość audiowizualną Hockneya, który prezentuje swoje dokonania wykorzystujące ruchomy obraz jako zarazem swoiste pendant oraz poszerzenie wystaw swoich prac plastycznych i fotograficznych. Artysta korzysta $z$ kamer cyfrowych w szczególny sposób ${ }^{45}$, jego zwrot w stronę ruchomego obrazu wiąże się z poszukiwaniem zarówno nowego dla niego medium kreacji, jak i przełożenia jego obserwacji teoretycznych dotyczących obrazu i obrazowania na nowy sposób rejestracji rzeczywistości. Filmując dziewięcioma albo osiemnastoma kamerami jednocześnie, nawiązuje zarówno do tworzonych przez siebie joiners, jak i malowanych przez siebie obrazów, takich jak A Bigger Grand Canyon (1998) czy cykl Bigger Trees Near Warter (2007), składających się z pięćdziesięciu elementów, do których namalowania wykorzystywał komputer jako narzędzie do czegoś, co można by nazwać preprodukcją albo przemalowaniem. To znaczy tworzeniem swego rodzaju siatki w komputerze, następnie wypełnianej już czysto malarskimi środkami jako obraz olejny na płótnie o bardzo dużych rozmiarach: $460 \mathrm{~cm} \times 1220 \mathrm{~cm}$. Te obrazy pochłaniają widza, ich immersyina natura powoduje, że zaciera się dystans pomiędzy światem obrazu i obserwatorem. Ale brakuje im tego, czego nie może zaoferować żaden obraz statyczny - ruchu. Dlaczego te przestrzenie (sam Hockney mówi o sobie jako o space freak'ul zostały namalowane, a nie sfotografowane? Między innymi dlatego, że żaden aparat nie jest w stanie (bez deformacji) zarejestrować tak szerokich planów.

Swoje eksperymenty z ruchomym obrazem Hockney rozpoczyna od skonstruowania systemu wykorzystującego dziewięć kamer zamontowanych na jadącym samochodzie. Może pojawić się skojarzenie z Nowa książka (1975), ciekawe zresztą, czy artysta widział film Zbigniewa Rybczyńskiego? Tyle że $\mathrm{w}$ tym przypadku kamery pracowały synchronicznie, natomiast u polskiego filmowca kolejne dziewięć sekwencji realizowanych było jedną kamerą. Zestawienie tych dwóch artystów, paradoksalnie, wcale nie musi wyglądać na czysto przypadkowe, jeśli pod uwagę weźmiemy teoretyczne zainteresowania

43 Zob. P. Zawojski, Kubrick w Muzeum (Narodowym), „Opcje” 2014, 3, s. 113-115.

44 Zob. P. Zawojski, Sztuka obrazu i obrazowania w epoce nowych mediów, Warszawa 2012, s. 118-142. W tej książce przedstawiam kondycję obrazów audiowizualnych w czasach dominacji nowych mediów, co może być znaczącym uzupełnieniem problematyki poruszanej w tym artykule.

${ }^{45}$ Sam określa swoje realizacje audiowizualne mianem digital movies. 
autora Traktatu o obrazie ${ }^{46}$, szczególnie zaś - jego poszukiwania w zakresie nowych sposobów przedstawień perspektywicznych. Krytyczne podejście do utrwalonych i zdeponowanych w logice działania aparatów technicznych sposobów rejestrowania ruchomych i nieruchomych obrazów to coś, co łączy poglądy obu twórców.

Realizacje Hockneya włączyć można w nurt filmu eksperymentalnego (dzisiaj cyfrowe narzędzia problematyzują użycie określeń film versus wideo, w tym miejscu nie jest to najistotniejsze), w którym nie chodzi o użycie kamer do zapisów własnych działań (forma dokumentacji) albo posłużenia się medium audiowizualnym bez wykorzystania jego artystycznych możliwości. Hockney swój zwrot w stronę ruchomego obrazu traktuje inaczej, to nie jest tylko użycie nowego narzędzia, to świadome rozwinięcie własnej praktyki jako twórcy obrazów. Tych zrealizowanych przez niego filmów eksperymentalnych (digital movies) jest raptem kilka: Winters zarejestrowane przy użyciu dziewięciu kamer i kolejne filmy składające się na Four Seasons (2011), pokazywane jako instalacja składająca się z czterech części, łącznie na trzydziestu sześciu wyświetlaczach 55-calowych; Seven Yorkshire Landscapes Videos (2011) zrealizowana przy użyciu osiemnastu kamer pracujących synchronicznie, podobnie jak The Jugglers (2014). To filmy stanowiące rodzaj medytacyjnego zapisu fizycznej przestrzeni ukazanej w niezwykły sposób: każda kamera zamontowana na jadącym samochodzie (jak na dolce) ma ustawiony inaczej kąt widzenia, rejestruje zatem rzeczywistość niejako tak jak mobilne oko ludzkie, które w swej ruchliwości nieustannie zmienia swój fokus, jednocześnie cały czas widzi ostro. Widzowie muszą swoim ruchomym widzeniem tworzyć własną ścieżkę poruszania się pomiędzy kolejnymi obrazami na wyświetlaczach albo spróbować ogarnąć wszystkie składowe projekcji jednym spojrzeniem, co zwłaszcza w przypadku ruchomych obrazów jest niezwykle trudne.

Wykorzystanie nowych możliwości stwarzanych przez tego typu „aparat” daje w efekcie zmultiplikowany obraz, przełamujący tradycyiną formę jednego punktu widzenia. To ujmowanie obrazu zarejestrowanej rzeczywistości w formie zwielokrotnionej, symultanicznej i narzucającej odmienny od tradycyjnego sposób percepcji. Czy mamy zatem do czynienia z rewolucyjną zmianą przedstawiania widzialnego świata? Oczywiście nie, to tylko rodzaj eksperymentu wizualnego (te rejestracje pozbawione są dźwięku), który wydaje się interesujący jako sposób testowania możliwości wyrazowych technologii cyfro-

46 Zob. Z. Rybczyński, Traktat o obrazie, Poznań 2009. Zob. też P. Zawojski, Studio Ideale - utopia (nie)zrealizowana?, w: Polska animacja w XXI wieku, red. M. Kozubek, T. Szczepański, Łódź 2017, s. 274-300. 
wych. Niespokojny duch ponadsiedemdziesięcioletniego artysty - dla którego użycie nowych narzędzi nie jest wyłącznie zmianą obszaru własnych poszukiwań związanych $z$ naturą obrazu, ale kolejnym krokiem w stronę nowego obrazowania - po raz kolejny daje o sobie znać. W tych działaniach nie ma niczego powierzchownego, mechanicznej aplikacji nowości technologicznych do rezerwuaru własnych działań w ramach sztuki ruchomego obrazu. Testowanie nowych narzędzi to rodzaj praktycznej weryfikacji jego przemyśleń teoretycznych, w wyniku czego powstały filmy interesujące, choć przecież ich wartość artystyczna może podlegać różnym ocenom.

Digital movies Hockneya to tylko kilka realizacji, tak jakby artysta doszedł do wniosku, że jego poszukiwania nowych form filmowego wyrazu mają ograniczony potencjał estetyczny. Jednak prezentując je na wspominanych już wystawach w Royal Academy of Arts oraz Young Museum w San Francisco, na których pokazywane były przede wszystkim jego obrazy malarskie, zwracał tym samym uwagę na różnorodne zależności i przenikania się w jego twórczości różnych mediów. Realizacje filmowe w inny sposób pokazują to, co zobaczyć można na jego płótnach, na nich zaś można dostrzec to, czego nie zauważamy, oglądając ruchome obrazy. To sposób na unaocznienie podobieństw i różnic wynikających z użycia różnych mediów.

Brytyjski artysta konsekwentnie poszukuje odpowiedzi na fundamentalne pytania związane z naturą obrazu, naszego widzenia, możliwości nowych mediów wizualnych i audiowizualnych. Jest bardzo rzadkim obecnie przypadkiem twórcy, któremu stale towarzyszy namysł nad teoretycznymi podstawami i implikacjami wynikającymi ze studiowania przeszłości i teraźniejszości obrazu. Zawodowi historycy, teoretycy i krytycy sztuki najczęściej odnoszą się krytycznie do jego publikacji, takich chociażby jak Wiedza tajemna; jego sądy, wyrażane często w formie dialogicznej wypowiedzi, prowokują do polemik. Do nielicznego grona autorów, którzy w pogłębiony sposób przedstawili rzeczowe kontrargumenty wobec "tezy Hockneya-Falco”, można niewątpliwie zaliczyć Michaela Johna Gormana ${ }^{47}$ i Davida G. Storka ${ }^{48}$. Gorman dostrzega pozytywny efekt kontrowersyjnych propozycji artysty i jego współpracownika przede wszystkim w tym, że Hockney i Falco zwrócili uwagę na nieco zapomniane narzędzia optyczne, takie jak camera obscura czy zwierciadła wklęsłe, które odegrały istotną rolę w historii malarstwa. Skupiając się na historii projekcji optycznych oraz pismach Giacoma Della Porty dowodzi, że nie ma

47 Zob. M.J. Gorman, Art, Optics and History: New Light on the Hockney Thesis, „Leonardo” 2003, 4(38), s. 295-301.

48 D.G. Stork, Optics and Realism in Renaissance Art, „Scientific American” 2004, 6(291), s. 77-83. 
przekonujących argumentow, by stwierdzić, że malarze korzystali z nich już w trzecim dziesięcioleciu XV stulecia, co jest kluczową tezą Hockneya. Stork z kolei podważa zasadnicze tezy Hockneya, wykorzystując techniki komputerowego rozpoznawania obrazów oraz analizę przedstawionego przez artystę systemu projekcyjnego, w którym zastosowano lustro wklęsłe. Podaje przy tym argumenty związane z ogniskową, jasnością wyświetlanego obrazu i perspektywą geometryczną, które dowodzą, że ustalenia Hockneya nie znajdują potwierdzenia w szczegółowej analizie obrazu Jana van Eycka Portret małżonków Arnolfinich (1434).

Czy zatem badania i koncepcje teoretyczne autora Historii obrazów należy potraktować wyłącznie jako ciekawostkę z pogranicza fikcji teoretycznych, spekulacji naukowych i alternatywnych wersji historii sztuki? Nie ulega wątpliwości, że Hockneya warto nie tylko oglądać, ale też słuchać i czytać, bo nawet jeśli nie musimy się z nim zgadzać, to niewątpliwie zawsze warto brać pod uwagę to, co ma do pokazania i do powiedzenia. W swoich eksperymentach fotograficznych i filmowych Hockney kontynuował tradycję zapoczątkowaną przez artystów renesansowych, którzy łączyli w swojej działalności dokonania artystyczne i rozmyślania teoretyczne nad podstawami tworzenia obrazów. Interesowały go przede wszystkim zagadnienia perspektywy, zmultiplikowanego punktu widzenia, kwestie przestrzeni i czasu w obrazie, jego joiners można potraktować zarówno jako antycypację kompozytowego tworzenia obrazów przy wykorzystaniu technologii cyfrowych, jak i próbę zredefiniowania istoty obrazu fotograficznego. Jego tradycyine rozumienie - według Hockneya - zdominowane zostało przez działanie aparatu ufundowane na zasadach perspektywy centralnej, która nie jest naukowym odtwarzaniem rzeczywistości, tylko rodzajem konwencji przedstawieniowej, teoretyczną abstrakcją. A przy tym aparaty wyposażone w szerokokątne obiektywy tworzą obrazy zniekształcające obiekty zarejestrowane na zdjęciach. W jego opinii joiners, a także zrealizowane przez niego eksperymenty filmowe, proponują inną perspektywę, bliższą naszemu faktycznemu postrzeganiu rzeczywistości, które opiera się na zmiennych punktach widzenia wynikających z ruchliwości oczu, co bliskie jest kubistycznemu pojmowaniu przestrzeni w obrazach. Kolaże fotograficzne to kompozycje o mozaikowej naturze, które mają oddać pozycję ruchomego widza, z wielu punktów widzenia obserwującego sfotografowaną postać, co tworzy rodzaj wizualnej narracji rozgrywającej się w czasie. Zasada "decydującego momentu” - sformułowana przez Henriego Cartiera-Bressona ${ }^{49}$, którego wybitne prace należą do innej epoki w foto-

49 Zob. H. Cartier-Bresson, Decydujacy moment, przeł. K. Łyczywek, „Format” 2005, $1-2$, s. 2-4. 
grafii - dziś całkowicie nie przystaje do rzeczywistości zdominowanej przez postprodukcję fotograficzną wykorzystującą rozmaite programy graficzne. W przypadku Hockneya tego typu działalność rozpoczęła się na długo przed tym, nim zaczął on korzystać z technologii cyfrowych. I choć efekty jego eksperymentów, podejmowanych w zakresie tworzenia obrazów fotograficznych, są dyskusyjne, to stanowią ważny epizod nie tylko w jego twórczości, ale i w historii fotografii.

\section{BIBLIOGRAFIA}

Baltrušaitis J., Anamorfozy albo Thaumaturgus opticus, tłum. T. Stróżyński, Gdańsk 2009

Bolsom E., Exhibiting Cinema in Contemporary Art, Amsterdam 2013

Cartier-Bresson H., Decydujacy moment, przeł. K. Łyczywek, „Format” 2005, 1-2, s. $2-4$

Claire J., Perspectives dépravées, w: D. Hockney, Dialogue avec Picasso, Paris 1999

Clark T.J., Picasso and Truth. From Cubism to Guernica, Princeton-Oxford 2013

Falco C.M., Optics and Renaissance Art, w: Optics in Our Time, red. M.D. Al-Amri, M. El-Gomati, M.S. Zubairy, New York 2016, s. 265-283

Falco C.M., Ibn al-Haytham and the origins of Computerized Image, <https://www. researchgate.net/publication/4319035_Ibn_al-Haytham_and_the_origins_of_ computerized_image_analysis > [dostęp: 8 lutego 2020]

Friedberg A., Wirtualne okno. Od Albertiego do Microsoftu, tłum. A. Rejniak-Majewska, M. Pabiś-Orzeszyna, Warszawa 2012

Gayford M., A Bigger Message. Conversation with David Hockney, London 2016

Gorman M.J., Art, Optics and History: New Light on the Hockney Thesis, „Leonardo” $2003,4(38)$, s. 295-301

Hammer M., Hockney as Philosophical Painter, w: David Hockney, red. C. Stephens, A. Wilson, London 2017

Hanhardt J.G, Bill Viola Interviewed by John G. Hanhardt, w: Bill Viola. Electronic Renaissance, red. A. Galansino, K. Perov, Firenze 2017

Hockney D., David Hockney on Photography: A Lecture at the Victoria and Albert Museum. November 1983, New York 1983

Hockney D., That's the Way I See It, London 1993

Hockney D., Wiedza tajemna. Sekrety technik malarskich dawnych mistrzów, tłum. J. Holzman, Kraków 2006

Hockney D., Gayford M., Historia obrazów. Od ściany jaskini do ekranu komputera, tłum. E. Hornowska, Poznań 2017

Hockney D., Picasso: Paintings of the '60, <https://www.guggenheim.org/wp-content/uploads/2018/08/9009139_01_9009140_01-Picasso-Paintings-of-the-1960s. pdf> [dostęp: 30 kwietnia 2020] 
Hockney D., Falco C.M., Optical Instruments and Imaging: The Use of Optics by $15^{\text {th }}$ Century Master Painters, < https://www.researchgate.net/publication/228924009_ Optical_instruments_and_imaging_The_use_of_optics_by_15th_century_master_painters > [dostęp: 8 lutego 2020]

Hockney D., Falco C.M., The Art of the Science of Renaissance Painting, <https:// wp.optics.arizona.edu/falco/wp-content/uploads/sites/57/2016/08/NatlGallery. pdf> [dostęp: 6 lutego 2020]

Hockney on Photography. Conversation with Paul Joyce, London 1988

Hoelzl I., Marie R., Softimage: Towards a New Theory of the Digital Image, BristolChicago 2015

Hoelzl I., Marie R., From Softimage to Postimage, „Leonardo” 2017, 1(50), s. 72-73

King G., Positioning Art Cinema. Film and Culture Value, London-New York 2019

Koepnick L., The Long Take. Art Cinema and the Wondrous, Minneapolis-London 2017

Lechowicz L., Historia fotografii, cz. 1: 1839-2009, Łódź 2012

Livingston M., David Hockney, London 1987

Panofsky E., Perspektywa jako "forma symboliczna”, tłum., wstęp i posłowie G. Jurkowlaniec, Warszawa 2008

Poprzęcka M., Inne obrazy. Oko, widzenie, sztuka. Od Albertiego do Duchampa, Gdańsk 2008

Ritchin F., In Our Own Image. The Coming Revolution in Photography. How Computer Technology is Changing Our View of the World, New York 1999

Rowley G., Principles of Chinese Paintings, Princeton 1974

Rybczyński Z., Traktat o obrazie, Poznań 2009

Stork D.G., Optics and Realism in Renaissance Art, "Scientific American” 2004, 6(291), s. 77-83

Sykes C.S., David Hockney. The Biography, 1975-2012. A Pilgrim's Progress, New York-London-Toronto-Sydney-Auckland 2014, s. 157-183

Szarkowski J., The Photographer's Eye, New York 1966

Tanaka M., Rethinking David Hockney's „reverse perspective”: The Acceptance of Japanese art in the 1970s and 1980, „Aesthetics” 2018, 21, s. 55-68

Vidler A., Warped Space. Art, Architecture and Anxiety in Modern Culture, Cambridge-London 2000

Vinci L. da, O malarstwie, tłum. L. Staff, Kraków-Budapeszt-Syrakuzy 2019

Weschler L., True to Life: Twenty-Five Years of Conversations with David Hockney, Berkeley-Los Angeles-London 2008

Zawojski P., Sztuka obrazu i obrazowania w epoce nowych mediów, Warszawa 2012

Zawojski P., Kubrick w Muzeum (Narodowym), „Opcje” 2014, 3, s. 113-115

Zawojski P., Studio Ideale - utopia (nie) zrealizowana?, w: Polska animacja w XXI wieku, red. M. Kozubek, T. Szczepański, Łódź 2017, s. 274-300

Zawojski P., Od obrazów (audiowizualnych) do postobrazów (hybrydycznych). Perspektywa teoretyczna, „Przegląd Kulturoznawczy” 2019, 1(39), <https://www.ejournals. eu/Przeglad-Kulturoznawczy/2019/Numer-1-39-2019/art/14649/ > [dostęp: 6 lutego 2020] 
Piotr Zawojski

University of Silesia, Katowice

PHOTOGRAPHY AND FILM IN ARTISTIC PRACTICE

AND THEORETICAL PROPOSITIONS OF DAVID HOCKNEY

\section{Summary}

In his diverse works, David Hockney has used, and still uses, various media, which in some periods of his activity gained leading significance, while in the following they were abandoned or temporarily abandoned. But no matter what medium in the given period was the main form of creativity, the focus of his interest has always been the issue of image and imaging. The article is devoted to the practice and theoretical recognition of photography, which was a kind of introduction to experiments with a moving image. The author refers to the artist's numerous publications on the theory and history of image and imaging (including Secret Knowledge, History of Images, On Photography). Photography led to Hockney's audiovisual realizations. This is a kind of repetition of the natural evolution and developmental progression of the media, also, and perhaps above all, in the technological dimension. The article is divided into three parts. In the first part, the author presents Hockney as a practitioner and theoretician, in whose activities both these activities are closely intertwined. This is a sign of the times: practice and theory are equally important, awareness of the medium, or artistic and aesthetic self-awareness of artists, is an expression of the spirit of the era in which an intuitive approach to art today seems inefficient, not to say impossible. Hockney appears to be an exemplary artist, who is extremely conceptual in his artistic practice as a consequence of his research on the history of art and a constantly developed set of his own theoretical findings. He is an artist discursively commenting not only on his work as an artist in many media (painting, drawing, graphics, set design, photography, film, computer graphics), but also an art and media theoretician reflecting on the fate of images in a changing media landscape. The second part of the article is devoted to the reconstruction of Hockney's theoretical reflections on photography and the analysis of his photographic projects. First of all, experimental Polaroid compositions created in the early eighties, named by the artist joiners, as well as photographic collages and photographic images realized in the later periods of the British artist's work. The third part considers digital movies, as Hockney calls them, audiovisual realizations referring to both his previous photographic works and experimental video films in which multi-camera systems are used.

Keywords:

David Hockney, joiners, photography theory, perspective, image, experimental film 